\title{
O externalismo semiótico ativo de C. S. Peirce e a CANTORIA DE VIOLA COMO SIGNO EM AÇÃO
}

\author{
Pedro Atã ${ }^{1}$ \\ João Queiroz ${ }^{2}$
}

RESUMO: O principal propósito deste trabalho é fornecer uma ontologia semiótica para redescrição do externalismo cognitivo ativo, desenvolvido recentemente pelo paradigma $4 \mathrm{E}$ (embodied, embedded, enactive, extended cognition). Nessa abordagem, sistemas cognitivos distribuídos (SCDs) são descritos como semiose, ou signos em ação. Explora-se a relação entre semiose e cognição, como concebida por C. S. Peirce, em associação com a noção de sistema cognitivo distribuído (SCD). Introduz-se a abordagem externalista peirciana, com ênfase na noção de distribuição temporal da semiose, e se descrevem SCDs, e seus elementos, como "açẫo dos signos". Para desenvolver esse argumento, examina-se um exemplo de SCD - improvisaçâo verbo-musical do repente, repentismo, ou cantoria de viola. Trata-se de um fenômeno de improvisação verbo-musical que tem a forma de um desafio em poesia oral versificada. Explicita-se esse fenômeno como a incorporação da estrutura formal de uma tarefa cognitiva e de um processo inferencial. Essa incorporação corresponde a uma semiotização das performances do repente como SCD. A tendência temporalmente distribuída do repente organiza o SCD como um sistema que realiza experimentos metassemióticos sobre a ação dos signos.

Palavras-chave: Sistema cognitivo distribuído. Externalismo ativo. Semiose. Repentismo. C. S. Peirce.

\section{INTRODUÇÃo}

O principal propósito deste trabalho é fornecer uma ontologia semiótica para o externalismo cognitivo ativo, como desenvolvido recentemente pelo

${ }_{1} \mathrm{PhD}$ researcher no Centre for Intermedial and Multimodal Studies, Linnaeus University, Vaxjo Suécia. (D) https://orcid.org/0000-0002-7123-3341 E-mail: ata.pedro.1@gmail.com

2 Professor Associado no Instituto de Artes, Universidade Federal de Juiz de Fora (UFJF), Juiz de Fora, MG - Brasil. (D) https://orcid.org/0000-0001-6978-4446 E-mail: queirozj@gmail.com

https://doi.org/10.1590/0101-3173.2021.v44n3.15.p177

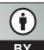


paradigma 4E (embodied, embedded, enactive, extended cognition) (NEWEN et al., 2018). Em nossa abordagem, sistemas cognitivos distribuídos (SCDs) são descritos como semiose, como signo em ação. Este trabalho aborda, portanto, as questôes: o que está distribuído na cognição distribuída? Como está distribuído? Utilizamos o fenômeno popular de improvisação verbo-musical conhecido como repente ou cantoria de viola como um exemplo de sistema cognitivo distribuído (SCD), e semiotizamos seus processos e componentes. A semiotizaçáo da cantoria, como um SCD, equivale, como veremos, a um profundo ajuste terminológico e metodológico, em termos descritivos, com diversas implicaçóes ontológicas, relacionadas à natureza da cantoria como um signo em ação.

$\mathrm{O}$ que tem sido chamado de paradigma $4 \mathrm{E}$, em ciência cognitiva, desloca o foco de investigação dos indivíduos, seus corpos e cérebros, para sistemas cognitivos distribuídos (SCDs) (HUTCHINS, 1995a; SPURRET, 2003; SUTTON, 2010; DAVIES; MICHAELIAN, 2016). Tais sistemas são constituídos não apenas por organismos dotados de agenciamento individual, mas também por artefatos e estruturas ambientais. ${ }^{3}$ São muitos os fenômenos investigados - laboratórios, bares, veleiros etc. O cockpit de um avião está entre os fenômenos mais mencionados (HUTCHINS, 1995b). Ele pode ser descrito como um SCD, cujo propósito é a pilotagem do avião. O sistema inclui a tripulaçáo, o piloto e o copiloto, instrumentos de voo e dispositivos externos de representação, como mapas, gráficos e diagramas, todos usados de acordo com normas bem estabelecidas.

Nesse caso, não apenas os indivíduos que compõem a tripulação incorporam processos cognitivos, mas o próprio ambiente incorpora tais processos. Um laboratório de ciência empírica também pode ser descrito como um SCD (NERSESSIAN et al., 2003). Ele é integrado por técnicos e pesquisadores, equipamentos, livros e manuais, relatórios, jornais especializados, instrumentos de observação e análise, modelos matemáticos e estatísticos. O próprio laboratório incorpora os processos cognitivos, não apenas seus pesquisadores. Nesses exemplos, processos fundamentais para o funcionamento do sistema acontecem fora dos corpos e das cabeças dos indivíduos.

\footnotetext{
${ }^{3}$ Nessa argumentação, tanto pessoas, ou organismos em geral, quanto artefatos externos e não biológicos podem ser considerados agentes. $\mathrm{O}$ agenciamento ao qual nos referimos não é, necessariamente, consciente e deliberativo, mas, em nossa descrição, semiótico, e corresponde à ação auto-organizada, não tutoriada, de signos. A ação de signos distribui-se entre cérebros, corpos e artefatos externos e materiais.
} 
A tese de que alguns processos cognitivos podem acontecer fora do corpo, através do uso e da manipulação de diversos dispositivos externos, é conhecida como "externalismo cognitivo ativo" (LAU; DEUTSCH, 2019). Esses dispositivos são chamados de artefatos cognitivos (HUTCHINS, 1999). Eles integram, auxiliam, apoiam, aprimoram ou melhoram a cognição (SUTTON, 2010). Somos capazes de alterar estados conscientes e a atenção, usando fármacos, "congelamos" e comunicamos o raciocínio, através do uso de alfabetos e sistemas de notação, organizamos, comparamos, calculamos e prevemos acontecimentos, por meio de números, estruturas algébricas, grafos e diagramas. Mas o artefato cognitivo considerado o mais importante é a linguagem, um dispositivo multinível de andaimes, profundamente incorporado (embodied), o qual aumenta radicalmente o que podemos fazer em termos de classificação, categorização, memória, inferência, aprendizagem, relaçôes sociais e instituiçôes (CLARK, 2005, 2006; SINHA, 2009, 2015).

Para o externalismo cognitivo ativo, os artefatos cognitivos são componentes náo biológicos ativos dos processos cognitivos. Existem diferentes visôes epistêmicas e ontológicas do externalismo (DAVIES; MICHAELIAN, 2016). Uma visão centrada no indivíduo ${ }^{4}$ define $S C D$ a partir de agentes individuais. Dessa perspectiva, SCDs são extensóes de um núcleo, localizado no organismo, seu sistema nervoso ou cérebro. Este é o caso da abordagem desenvolvida por Andy Clark e David Chalmers (1998), ou "cognição estendida”, segundo a qual os agentes cognitivos individuais se acoplam a artefatos, ampliando suas mentes para além de seus limites biológicos. $\mathrm{O}$ foco, nesse caso, é um agente, um organismo individual, e suas extensóes (CLARK, 2010).

Para Hutchins (2011), o externalismo de Clark falha, ao não explicar o papel crucial da cultura. Uma narrativa enculturada da cognição distribuída não se concentra em como a cognição se estende a partir do indivíduo em direção a artefatos, mas em como múltiplos indivíduos e artefatos estão organizados em ecossistemas culturais (HUTCHINS, 2011, 2014). Hutchins (2014, p. 36) caracteriza a cognição distribuída como uma abordagem emergentista. Concordamos que o externalismo precisa ser enculturado, com implicações emergentistas. Uma posição emergentista sugere a organização do sistema como o principal componente explanatório. Não se pode falar em agenciamento

\footnotetext{
${ }^{4}$ Davies e Michaelian (2016) nomeiam essa visão de "centrada no agente". Para manter certa coerência com a noção de agente, como usada em nossa abordagem, chamamos a abordagem de "centrada no indivíduo".
} 
individual precisamente porque o sistema é auto-organizado, ${ }^{5}$ e porque ele exibe propriedades emergentes. Entretanto, embora o emergentismo forneça uma orientação explanatória robusta, ele não responde à questão sobre como devemos entender o externalismo cognitivo ativo de maneira enculturada, deslocando o agente individual do centro focal da abordagem. Necessitamos de uma descrição mais precisa do que emerge e de como isso acontece.

Uma tentativa de definir SCDs, que se recusa a concentrar sua explicação no indivíduo, é a "abordagem baseada em tarefas", de Davies e Michaelian (2016). Uma "abordagem baseada em tarefas" começa identificando uma tarefa cognitiva (Davies e Michaelian caracterizam uma tarefa como "processamento de informaçôes"), incluindo os indivíduos e os artefatos que participam dos fluxos relevantes de informaçôes. Na descrição de Davies e Michaelian, se a informação flui entre as entidades e é usada para resolver uma tarefa, essas entidades, independentemente de serem internas ou externas aos organismos, podem ser consideradas partes do SCD, com relação à tarefa especificada. Davies e Michaelian (2016) sugerem que essa abordagem, baseada em tarefas para identificação dos SCDs, permite aumentar (zoom-in) e diminuir (zoomout) a escala de observação. As tarefas podem ser divididas em subtarefas, ou examinadas como partes de tarefas, e metas, mais abrangentes. Como as tarefas definem os SCDs, elas possibilitam fácil escalonamento dos SCDs. Um SCD pode ser reduzido e concentrar-se apenas em algumas das estruturas neurais no cérebro de um indivíduo; ou pode ser estendido, para incluir múltiplos agentes, cérebros e artefatos, os quais interagem para resolver grandes tarefas. Assim, o mesmo agente pode participar em diferentes SCDs, e um SCD pode incluir vários agentes.

Davies e Michaelian (2016) deslocam, portanto, o indivíduo do centro do processo externo. Mas os autores não caracterizam o que é uma tarefa cognitiva, ou "processamento de informação". Uma tarefa cognitiva funciona como um fator de organização capaz de reunir elementos para formar um sistema distribuído, como uma entidade ou processo que tem alguma forma de existência. Embora ofereça uma ferramenta para identificar SCDs, a abordagem não fornece uma explicação sobre o que é um sistema cognitivo distribuído. Permanece, portanto, obscuro qualquer detalhamento sobre sua ontologia, que semiotizamos aqui.

${ }^{5}$ Auto-organização é um processo que ocorre principalmente em sistemas complexos compostos por entidades em interação que afetam mutuamente o processo da outra, levando o sistema a um estado ordenado e provisoriamente estável, ou seja, um estado de variabilidade e ambiguidade reduzidas (KELSO, 1995). 
Embora diversos autores tenham defendido a necessidade de enculturar a abordagem externalista, o paradigma ainda não considerou seriamente que SCDs incorporam significados, e não simplesmente processamento de informaçóes. ${ }^{6}$ Para sermos mais precisos sobre o problema que mais nos interessa aqui, a noção de SCD ainda não foi associada a uma teoria do significado capaz de explicar o caráter distribuído da cognição. Sugerimos - e este é o principal propósito deste artigo - que o componente explanatório que falta ao externalismo cognitivo não centrado no indivíduo é a noção pragmatista de semiose (ação de signos) de Peirce. ${ }^{7}$

$\mathrm{Na}$ próxima seção, exploramos a relação entre semiose e cognição. Em seguida, descrevemos, em duas etapas, um exemplo de SCD, o repente, repentismo ou cantoria de viola. O repente é uma improvisação verbo-musical, popularmente praticada no Nordeste do Brasil, que assume a forma de um desafio em poesia oral versificada. Ele pode ser descrito como um SCD envolvendo poeta-cantadores que improvisam, o público ou audiência, incluindo os chamados "apologistas", ${ }^{8}$ produtores e curadores, e vários artefatos cognitivos (microfone, palco, viola, estruturas de versificação e prosódicas etc.). Descrevemos os repentistas, e o próprio fenômeno da cantoria de viola, como SCDs que incorporam a estrutura formal de uma tarefa cognitiva. Em seguida, explicitamos o fenômeno como semiose. Essa abordagem corresponde à semiotização de um SCD.

\section{Semiotica Cognitiva de Peirce}

Em outros trabalhos, temos defendido que, contra qualquer forma de internalismo, Peirce pode ser considerado um precursor da tese da mente estendida e da cognição distribuída (ATÁ; QUEIROZ, 2013, 2014). Como Kirsh (2009, p. 297) enfatiza, "Peirce mencionou pela primeira vez essa ideia - indivíduos usam objetos externos para pensar - no final do século XIX, quando ele afirma que os químicos pensam tanto com seus tubos de ensaio quanto com caneta e papel."

\footnotetext{
6 Para uma distinção entre informação e semiose, ver Queiroz et al. (2011).

7 Seguimos a prática de citar os Collected Papers de Charles Sanders Peirce (Peirce, 1931-1935, 1958) pelo número do volume e número do parágrafo, precedidos pelo CP; o Essential Peirce, por número de volume e número de página, precedido por EP. As referências ao Annotated Catalogue of the Papers of Charles S. Peirce (1967) serão indicadas pelo MS, seguidas pelo número e pelas páginas do manuscrito.

8 Apologistas são entusiastas "especializados", declamam muitos repentistas, lembram episódios memoráveis de desafios que ficaram famosos e conhecem, em detalhes, a história de muitos cantadores.
} 
A semiótica cognitiva de Peirce descreve a mente como um processo dialógico que não pode ser dissociado da comunicação situada e ativamente distribuída (CP 6.338). Sua abordagem da semiose está relacionada a tentativas formais de descrever processos cognitivos em geral. Ela fornece (i) um modelo pragmatista da ação dos signos, (ii) uma concepção da mente como um processo de interpretação de signos (RANSDELL, 1977; COLAPIETRO, 1989; BERNSTEIN, 2010) e (iii) uma lista de variedades fundamentais de signos baseada em uma teoria de categorias lógico-fenomenológicas (HOOKWAY, 1985, p. 125). De acordo com Peirce, os processos cognitivos dependem fundamentalmente de processos semióticos. ${ }^{9}$ Ainda mais radicalmente, eles coincidem - a mente é um processo de ação de signos ou semiose. Não podemos pensar exceto através de signos (MS [R] 654: 3; EP 1:30; CP 1.538, $5.265,6.338$ ). Essa tese foi elaborada, pela primeira vez, como um ataque ao cartesianismo, em uma série de artigos publicados entre 1868 e 1869 (W 2:193-241).

A semiótica de Peirce oferece, simultaneamente, de acordo com uma posiçáo processualista, uma teoria do significado e uma teoria da mente. Ela faz parte de uma filosofia de processos, principalmente seu sistema filosófico tardio, desenvolvido a partir de 1903 (QUEIROZ; STJERNFELT, 2019). Uma filosofia de processos preocupa-se com a dinamicidade, complexidade e emergência, como princípios ontológicos e epistemológicos fundamentais (SEIBT, 2018)..$^{10}$ A filosofia processualista de Peirce baseia sua teoria do significado com foco na ação dos signos, em contraste com teorias cujos focos são a própria representação ou signo (formalistas e estruturalistas), ou seus usuários (sociológica, psicológica, neurocognitiva). ${ }^{11}$ A semiose é concebida como uma relaçáo triádica, na qual a açáo de um signo, que se encontra em uma forma de determinação com um objeto, gera um efeito em um intérprete, chamado de interpretante, que pode ser outro signo.

\footnotetext{
9 Devemos fazer uma observação sobre o uso do termo semiótica. Como De Waal (2013, p. 75) indica, o próprio Peirce nunca usou o termo semiotic, mas variantes: semeotic, semeiotic, semeiotics. Embora semiótica não tenha sido a solução proposta por Peirce, ela se tornou padrão na área e, por esse motivo, nós a adotamos aqui.

${ }^{10}$ Não há, evidentemente, espaço para exibir aqui toda a profusão de tendências, correntes e subcorrentes que caracterizam o que é chamado de "filosofia de processo», de Heráclito a Whitehead, de suas origens às novas tendências em filosofia da ciência. Para uma abordagem recente dessa profusão, em diversas áreas, recomendamos Nicholson e Dupré (2018), Hooker (2011), Weber e Weekes (2009), Rescher (1996).

${ }^{11}$ Sobre como o pragmatismo e a filosofia de processos de Peirce se apoia na tese metafísica do sinequismo, indicamos Esposito (2005), Murphey (1993).
} 
Eis algumas das premissas da teoria do signo de Peirce:

- Triadicidade (irredutibilidade triádica): a semiose é uma relação triádica cuja propriedade emergente é o significado. A relação é caracterizada como triádica, porque um primeiro termo (signo) é "determinado" (DE WAAL, 2013, p. 80) por um segundo termo (objeto), de modo a produzir, em uma quase-mente, um efeito interpretativo (interpretante), o qual pode ser outro signo (CP 4.536). Essa relação entre três termos não pode ser reduzida ou simplificada. Em uma tríade irredutível, o que coordena os termos da relação não é um agrupamento de relaçôes diádicas. Qualquer relação entre o signo e seu objeto é intérpretedependente. "Intérprete", aqui, não se refere necessariamente a um indivíduo, mas a qualquer tipo de sistema cognitivo, sem restrição à sua natureza - físico-químico, biológico ou computacional (QUEIROZ et al., 2011).

- Dinamicidade: a semiose é um processo dinâmico, com signos que produzem outros signos, ou interpretantes. Como Savan (1986, p. 134) argumenta, um interpretante é tanto o terceiro termo de uma relação triádica quanto o primeiro termo (signo) de uma relação triádica subsequente. Mesmo as atividades de um único agente, isolado, incorporam um processo dinâmico de comunicação. A estabilidade temporal da semiose não é entendida como stasis (estados representacionais estáticos), mas como regularidade do signo em ação.

- Emergência: a semiose é um processo auto-organizado, emergente, em um sistema complexo de usuários de signos que interagem localmente. ${ }^{12}$ A semiose emerge durante interaçóes locais entre agentes distribuídos (enunciadores e intérpretes). Um evento de comunicação envolve, de forma irredutível, um enunciador, um signo e um intérprete, em que o enunciador comunica um hábito (padrão estável de restriçóes), através do signo, para um intérprete. Em uma comunicação, “[...] é conveniente falar como

\footnotetext{
${ }^{12}$ Em outros trabalhos, exploramos a tese da "semiose como propriedade emergente", tanto de uma perspectiva estritamente filosófica (QUEIROZ; EL-HANI, 2006; EL-HANI; QUEIROZ, 2005), e diretamente associada às formulaçôes peircianas (ver também ROSENTHAL, 1994), quanto de uma perspectiva computacional (LOULA et al., 2010, GOMES et al., 2007) e histórica (ATÃ; QUEIROZ, 2019).
} 
se o signo tivesse se originado de um enunciador e determinado seu interpretante na mente de um intérprete." (MS 318: 11).

A teoria sugere um tipo extremo de externalismo cognitivo ativo - assim como para Peirce é impossível pensar sem signos, é impossível o pensamento sem a incorporação material de algum aspecto do signo. Como a semiose é um processo dinâmico, a incorporação material é temporalmente distribuída. Sua semiótica cognitiva se preocupa com a distribuição tanto espacial quanto temporal, mas as propriedades mais definidoras da semiose estão relacionadas à distribuição temporal: "[...] dizer, portanto, que o pensamento não pode acontecer em um instante, mas requer tempo, é outra maneira de dizer que todo pensamento deve ser interpretado em outro, ou que todo pensamento é em signos." (CP 5.253).

A semiose é um processo tempo-dependente, histórico e evolutivo, e se desenvolve em várias escalas de observação. A descrição de um "signo" não corresponde à descrição de uma entidade dotada de certas substâncias, porém, à descrição de um processo cujas propriedades são irredutíveis às propriedades sincrônicas das entidades que instanciam o processo. Em nossa abordagem, a semiose é incorporada em sistemas cognitivos distribuídos como uma tendência para gerar interpretantes. Conforme o externalismo semiótico ativo, a cognição equivale ao desenvolvimento de artefatos disponíveis, em que está incorporada como um poder para produzir interpretantes. A cognição assume a forma do desenvolvimento de artefatos cognitivos, como ferramentas de escrita, instrumentos de observação, sistemas notacionais, segundo foi salientado por Skagestad (2004), e por Ransdell (2003), com relação à noção de inteligência aumentada.

\section{REPENTE}

O repente, cantoria de viola ou repentismo é uma tradição caracteristicamente nordestina de improvisação verbo-musical, a qual tem a forma de um desafio em poesia oral versificada. Esse tipo de desafio popular de improvisação é um fenômeno que se manifesta sob várias maneiras, em todo o mundo. Câmara Cascudo (2004), pioneiro em estudos etnográficos e antropológicos do repente, no Brasil, descreve o repentista como um descendente do aedo grego, do gree anglo-saxão, do moganis e meris árabe, dos 
bardos armoricanos, dos skalds escandinavos, dos menestréis e trovadores da Idade Média. O repente, ou cantoria, existe no sertão nordestino, ao menos desde meados do séc. XIX, tendo surgido na região do Pajeú pernambucano e do Cariri paraibano, e tendo como principais cidades Itapetim-PE, São José do Egito-PE, Tabira-PE, Monteiro-PB, Patoser-PB, entre outras. Elas formam o que é considerado "quadrilátero da poesia" cantada (WILSON, 1986).

Praticantes do repente são chamados de repentistas, cantadores ou violeiros. Os termos indicam diferentes atividades de um repentista, relacionadas à improvisaçáo, ao canto e à viola. Os termos repentista e cantador, em particular, enfatizam diferentes aspectos da atividade improvisacional:

As palavras "repentista" e "cantador" são usadas com o mesmo significado na maioria das situaçôes. Entretanto, quando se quer realçar diferenças técnicas e características próprias de cada um, se distingue entre as duas. É considerado "cantador grande" aquele que segue a oração no planejamento das estrofes, possui bagagem e a utiliza bem na formulação de imagens poéticas - a ênfase aí está na relação com as regras e modelos incorporados da poesia. Já o "repentista grande" é aquele que se notabiliza por respostas rápidas ao que o parceiro canta e a incidentes no ambiente da cantoria, muitas vezes iniciando suas estrofes sem ter um roteiro certo - recaindo maior peso na relação com a situação do fazer poético. Todo cantador repentista (no sentido amplo) é cantador e repentista (no sentido estrito), mas há os que se sobressaem mais em uma ou outra dimensão da arte. (SAUTCHUK, 2009, p. 64).

As sessões são chamadas de cantorias. Festivais organizados de cantoria são comuns em todo o Nordeste do país. Em uma performance, há tipicamente dois poetas-cantadores, cada um deles equipado com sua própria viola. Eles se revezam, gerando versos de acordo com regras rigorosas de metrificação. As restriçóes métricas estabelecem a distinção entre os gêneros, os quais são muitos, embora cerca de dez sejam os mais difundidos (OLIVEIRA, 1999, p. 52-53). O que um gênero informa é, principalmente, uma estrutura métrica de versificação, número de sentenças e estrutura de rimas em cada estrofe.

$\mathrm{O}$ repente possui um aspecto competitivo. No tipo mais comum de festival, o enfrentamento acontece entre duplas de cantadores. Diferentes duplas improvisam, recebendo notas de um júri especializado, e a dupla com maior pontuação vence o festival. Mas a competição também pode ser individual (e.g. Festival estado contra estado). Nesse caso, repentistas enfrentam seus próprios parceiros, nas duplas, e o júri decide o melhor cantador para a 
próxima fase. Mas a cantoria não está restrita apenas aos festivais. $\mathrm{O}$ mais tradicional tipo de evento chama-se "cantoria pé-de-parede". Uma dupla de cantadores se apresenta para uma audiência, sem júri especializado, em geral a convite de um anfitrião. Mesmo em situações em que não há uma competição institucionalizada, ou em que o verso não orienta o tema de um desafio, a cantoria tem um caráter de disputa, em que um cantador tenta superar seu oponente, diante de uma plateia (SAUTCHUK, 2009, p. 159-161). Para isso, os cantadores devem demonstrar suas habilidades, improvisando versos metrificados e rimados, de acordo com um tema sugerido (SAUTCHUK, 2011).

A audiência desempenha um papel importante na avaliação (SAUTCHUK, 2009), reagindo negativamente aos erros e imprecisóes (hesitaçôes, inconsistências métricas, rimas fracas, repetições temáticas, dificuldade para desenvolver um tema ou para responder ao adversário) e destacando movimentos hábeis, desenvolvimentos temáticos criativos, versos perfeitamente metrificados, feitos fluentemente e sem hesitação, rápido tempo de reação, desafios pessoais provocativos e respostas para esses desafios. Em festivais organizados, a competição é mais formalizada, com temas aleatoriamente selecionados e um júri especializado, o qual proclama um vencedor (SAUTCHUK, 2009, p. 133-136).

\section{A CANTORIa É UM SISTEMA COGNITIVO DISTRIBUído}

A cantoria, ou repente, pode ser descrita como um sistema cognitivo distribuído. Tal abordagem salienta como a atividade, que é uma prática cognitiva e cultural, está situada em um ambiente de artefatos e restriçóes materialmente incorporados. Exemplos de cognição distribuída, em diferentes domínios, incluem, entre outros: operações numéricas (ZHANG; WANG, 2005; BENDER; BELLER, 2017), quebra-cabeças (KIRSH, 2009; ZHANG; NORMAN, 1994), prática e aprendizagem científicas (PANDE; CHANDRASEKHARAN, 2017; NERSESSIAN et al., 2003; NERSESSIAN, 2008), tarefas conjuntas de solução de problemas criativos (BJORNDAHL et al., 2014). No caso da cantoria, e seguindo a abordagem baseada em tarefas de Davies e Michaelian (2016), um SCD pode ser identificado com a tarefa cognitiva que realiza - produzir um diálogo improvisado em uma cantoria. As subtarefas incluem, em nosso exemplo, compor, cantar e avaliar versos improvisados. Enquanto a tarefa geral do diálogo improvisado define a 
cantoria como um SCD, as subtarefas definem SCDs de menor escala, como um cantador individual, e sua própria viola, a dupla de cantadores e o público. Estamos, aqui, especialmente interessados em uma escala maior de descrição.

Realizar e avaliar o diálogo improvisado em uma cantoria pode ser descrito como uma tarefa de solução de problemas. Uma solução de problemas (NEWELL; SIMON, 1972) consiste em passar do estado inicial de um problema para seu estado final, de acordo com movimentos permitidos determinados por regras. Não é necessário que as regras sejam declaradas. Elas também podem ser uma consequência das propriedades físicas dos materiais de que são feitas, ou como são usadas na tarefa de solução de problemas. ${ }^{13}$

Uma distinção bem conhecida na teoria de solução de problemas é entre problemas bem e mal definidos. Problemas bem-definidos, como quebra-cabeças clássicos, possuem regras e estados facilmente identificáveis. Mas, o que é ainda mais importante, eles possuem um conjunto de soluçôes não ambíguas. Diferentemente, um problema maldefinido pode ter: (i) um gradiente variado de soluçóes adequadas; (ii) nenhuma solução conhecida de antemão e, nesse caso, parte da tarefa do solucionador é desenvolver o que vale como uma melhor resposta; (iii) nenhum conjunto fixo de regras e, portanto, nenhum conjunto fixo de escolhas, consequências das escolhas e avaliação das escolhas (KIRSH, 2009, p. 268). Na abordagem clássica de solução de problemas, os problemas podem ser definidos como determinantes, para seus solucionadores, de uma estrutura formal abstrata que não varia através de diferentes instanciaçôes da tarefa. Uma abordagem diferente é a solução situada de problemas, relacionada às influências locais e contextuais das tarefas, de modo que a estrutura formal de um problema é decisivamente instanciada e dinamicamente acoplada aos artefatos materiais, e é dependente das atividades disponíveis ao solucionador, em uma determinada situação (KIRSH, 2009, p. 271).

A cantoria é exemplo de uma tarefa de solução de problemas maldefinida e situada. Ela é maldefinida, porque é uma tarefa que não possui um conjunto fechado de soluçóes, embora possua um conjunto fixo de regras, e é situada, porque a estrutura formal da tarefa (operaçóes realizadas para solução do problema) é dependente da materialidade dos artefatos usados: os cantadores estruturam e resolvem problemas "com" e "por meio de" seus

${ }^{13}$ Para ver exemplos de regras materialmente dependentes, em versôes da "Torre de Hanoi”, cf. Zhang e Norman (1994). 
poemas (estruturas formais e temáticas) e violas. Há, ao menos, quatro tipos de restriçóes que constituem a estrutura formal da tarefa:

- Restriçóes temporais: os cantadores não podem demorar para compor os versos. Quando um cantador termina de cantar uma estrofe, seu opositor tem apenas alguns segundos para começar a cantar, caso contrário, é avaliado como hesitante.

- Restriçóes métricas e rímicas: os cantadores devem respeitar estruturas rígidas de versificação - posição e distribuição das tônicas em cada verso, número de versos em cada estrofe, padrão e estrutura de rimas.

- Restrições temáticas: cantadores devem dialogar sobre um tema específico e desenvolver esse tema, ao longo da performance. Nesse diálogo, eles devem adicionar novos fatos, de maneira surpreendente. Essa restriçáo impede o uso de versos memorizados. Como os cantadores não sabem, com antecipação, os temas sobre os quais devem improvisar, não podem preparar versos específicos.

- Restriçôes dialógicas/situacionais: os cantadores devem dialogar, reagindo aos versos do oponente. Responder e reagir, com fluência, a uma situação imediata é uma demonstração de habilidade.

Em uma cantoria, essas restrições estão incorporadas em artefatos cognitivos. Os cantadores usam ferramentas específicas para "aliviar o custo" cognitivo criado por tantas, e táo complexas, restriçôes. As ferramentas são emblemáticas: a viola, as toadas (estruturas melódicas e prosódicas), os motes e as "deixas" (sugestôes ou "ganchos").

A viola característica dos repentistas é responsável pelo acompanhamento instrumental dos versos cantados (SAUTCHUK, 2009, p. 37-39). Em uma cantoria, a viola é usada para executar o que é chamado "baião-de-viola", um ciclo repetitivo de dois acordes alternados (tipicamente Lá e Mi), com pequenas variaçóes e de acordo com um padrão rítmico bem estabelecido. Eventualmente, pequenos fragmentos melódicos podem ser inseridos, mas nunca são desenvolvidos. Na maioria das vezes, um cantador toca a viola enquanto o oponente está improvisando e durante o curto intervalo em que ambos estáo em silêncio, interrompendo, porém, quando iniciam o improviso. 
O período em que o cantador toca a viola é precisamente o período em que ele está compondo a estrofe seguinte. Os cantadores compóem seus versos retroativamente, de trás para frente, preparando rapidamente os versos finais, enquanto o oponente improvisa (SAUTCHUK, 2009, p. 85). O papel da viola é visto como crucial, na cantoria. Oliveira (1999, p. 98) sugere que ela ocupa um papel de offloading cognitivo: "Sem a viola o cantador não será capaz de executar: a viola é como uma arma, de forma que modifica o pensamento do cantador, focalizando a mente nos versos, no público e no ambiente como um todo."

O baião-de-viola ajuda a descarregar (offloading) restrições métricas e temporais. Ele fornece a estrutura da improvisação (OLIVEIRA, 1999, p. 129) e a referência rítmica para o diálogo, com os ciclos dos acordes alinhados com os pulsos e acentos dos versos (SAUTCHUK, 2011, p. 39). O baiáode-viola também informa ao repentista o momento de iniciar, usualmente depois de dois ou três ciclos. Trata-se igualmente de uma externalização material do intervalo de tempo usado para compor os versos, permitindo que o público avalie sua performance, em termos de ciclos executados. Além disso, o baião-de-viola tem função fática de preservar o ritmo e a intensidade da comunicação, durante pausas ou intervalos, como pausas respiratórias, quando o cantador interrompe o improviso para pensar (SAUTCHUK, 2011, p. 39). As toadas são as linhas melódicas predeterminadas que os cantadores seguem ao cantar os versos, submetidos às exigências rítmicas (RAMALHO, 2001, p. 27). Assim, as toadas estão entre os principais artefatos usados para materializar as restriçóes métricas e rítmicas. Para Sautchuk (2011, p. 79), os cantadores aprendem a metrificar os versos, aprendendo a ouvir e a imitar estruturas prosódicas e métricas dos padróes de cantoria.

As toadas estão ligadas aos diferentes gêneros. O que um gênero informa é, principalmente, uma estrutura métrica de versificação - quantidade de sílabas, distribuição rítmica e padrão de tônicas em um verso, número de linhas e estrutura de rimas em cada estrofe. Um único evento de cantoria pode incluir muitos gêneros. Cada gênero possui seu acervo de toadas. As variaçóes prosódicas de uma toada atuam sobre as sílabas poéticas, o padrão de acentos e rimas. Encontrando versos que se encaixam nas toadas, os cantadores podem respeitar as restriçôes métricas de um gênero e, variando as toadas, podem improvisar em diferentes gêneros. A toada externaliza os cálculos feitos sobre as sílabas, transformando-os em tarefa mais simples - encaixar palavras em padróes melódicos, rítmicos e prosódicos. A alternância entre a toada cantada 
e o baiáo-de-viola, o qual aparece em primeiro plano após o canto e volta ao fundo, durante a apresentação, fornece a estrutura geral da cantoria.

Alguns gêneros usam motes (mottos). Um mote é normalmente composto por dois versos, sobre os quais o cantador deve improvisar (SAUTCHUK, 2011, p. 28-29). Um mote é atribuído, por solicitação do público ou, nos festivais, por algum procedimento de randomização, a uma dupla de cantadores, constituindo uma restrição temática e métrica à improvisação. Os cantadores devem improvisar estrofes que conduzem ao mote. Ele é um dispositivo que garante que os cantadores permaneçam no escopo do tema. O mote "descarrega" (offloading) o custo do desenvolvimento temático, encapsulando-o em um único objetivo de solução de problemas - construção de uma estrofe em que cabe o mote. Ele também estabelece restriçóes métricas, porque fornece uma estrutura rítmica, a qual deve ser seguida pelos cantadores. Gêneros de repente que não usam motes podem usar "deixas" (dicas, "ganchos" ou palavras-chave). Nesses gêneros, o repentista deve "seguir a sugestão" do último verso da estrofe cantada pelo oponente, e fazer o primeiro verso da sua estrofe de resposta rimar com ele.

Um bom exemplo é a sextilha, considerado um dos gêneros mais fáceis, normalmente cantado no início de uma sessão de cantoria. ${ }^{14} \mathrm{~A}$ estrofe de uma sextilha é composta por seis versos, de sete sílabas em cada verso, em que rimam o segundo, quarto e sexto versos. A resposta a uma estrofe de sextilha deve começar a rimar com a estrofe anterior, ou seja, com a estrofe recémimprovisada pelo oponente, criando um sentido de continuidade entre as estrofes. A "deixa” cria uma sucessão formal de rimas e o desafio de resposta a uma rima criada pelo oponente (SAUTCHUK, 2011, p. 27). Ela também restringe a composição dos versos. Nos gêneros que usam a deixa, o repentista recebe um "ponto de partida" - a deixa deve se encaixar na primeira linha do verso da estrofe, em contraste com o "ponto final" do mote.

A viola, as toadas, o mote e a deixa são ferramentas (ou artefatos cognitivos) usadas na tarefa de solução de problemas situados de uma cantoria. Elas ajudam a externalizar e a descarregar as restriçóes temporais, métricas e rímicas, temáticas, dialógicas e situacionais que constituem a estrutura formal da tarefa de solução de problemas situados da cantoria. Essa tarefa define

\footnotetext{
${ }^{14}$ Assinala Severino Feitosa (entrevista): "A Sextilha é uma espécie de ritual da cantoria. Só se começa uma cantoria, até onde eu tenho conhecimento, com uma Sextilha. Você vê que até mesmo os festivais se abrem com uma Sextilha. Até numa apresentação que nós vamos fazer tem que se abrir com uma Sextilha. Pode haver outras modalidades, mas se abre cantando Sextilha." (OLIVEIRA, 1999, p. 56).
} 
o sistema cognitivo distribuído de uma cantoria, envolvendo indivíduos (cantadores, audiência, avaliadores) e artefatos (violas, toadas, motes, deixas) no processo de solução de problemas. Essa descrição apoia-se no paradigma baseado em tarefas de cognição distribuída e descreve como um sistema de indivíduos e artefatos pode incorporar uma estrutura formal que conduz à solução, ou à conclusão, de uma tarefa cognitiva. De uma perspectiva peirciana, o que falta nessa descrição é uma versão dos processos de significação envolvidos. Como a cantoria é um processo que envolve signos em ação?

\section{A CANTORIA COMO SEMIOSE}

A descrição da cantoria como sistema que distribui a atividade cognitiva da improvisação não captura sua propriedade mais importante - atividade cultural que envolve significado. Podemos perguntar: o que é distribuído em uma cantoria? Nossa resposta é que não se trata apenas de um conjunto de práticas em direção a um objetivo convencionalizado. São processos de significação. Para uma abordagem semiótica peirciana, não basta considerar a cantoria como um sistema distribuído de agentes e artefatos cognitivos. É preciso levar em conta como indivíduos e artefatos incorporam processos semióticos. O componente explanatório primitivo é a semiose. A etapa mais relevante, portanto, passa a ser o exame de como um SCD incorpora a semiose.

Note-se que não se trata apenas de uma redescrição da performance de indivíduos e artefatos. $\mathrm{O}$ objeto da descrição não são os próprios indivíduos e artefatos, mas um processo geral, irredutível aos seus componentes e propriedades particulares. Dessa perspetiva, quando nos referimos a um indivíduo ou artefato cognitivo, estamos nos referindo a signos em ação, a semiose. É o caso das violas, toadas, motes, deixas, cantadores, curadores, apologistas e a própria audiência, os componentes e os processos de um SCD. Isso equivale a uma semiotização da cognição distribuída.

A semiotizaçáo representa um incremento à abordagem de Hutchins (2011, 2014) da cognição distribuída como uma versão emergentista e enculturada. Em nossa descrição, o que emerge, e organiza, os SCDs é algo que não se confunde com os componentes observados no sistema. O objeto da descrição não existe como algo (ou coisa), mas como um processo (RESCHER, 1996; BICKHARD, 2011; SEIBT, 2018). A distinção entre coisas e processos indica dois modos de existência. Uma coisa pode existir independentemente da ação, contudo, o modo de ser de um processo é a própria ação. Como 
afirmam Dupré e Nicholson (2018, p. 15), “[...] você pode deixar sua máquina de escrever em um loft vazio e retornar uma década depois e começar a usá-la novamente. Mas se você acidentalmente deixar seu hamster no sótão, você não terá um hamster por muito tempo." Um organismo está sempre agindo, e não pode deixar de fazê-lo. A semiose é, para um SCD, o que o metabolismo é para um organismo.

O que define e individualiza um SCD, em nossa abordagem, é a semiose, cuja existência processual se incorpora na ação dos componentes do SCD. Ele não pode ser tratado como um de seus componentes, e não pode ser exaustivamente descrito como uma coleção deles (agentes e artefatos), nem como uma coleção de seus estados representacionais. O sistema se confunde com uma sequência dinâmica, contínua, de ações e atividades acopladas, as quais não podem ser caracterizadas por uma enumeração de eventos e coisas, mas por propriedades lógicas do processo (semiose), que os componentes do SCD, individualmente, não possuem: irredutibilidade triádica (EP 2: 171; CP 5.484; BRUNNING, 1997; BURCH, 1997), processualidade (CP 5.484; ATKIN, 2016, p. 132; QUEIROZ; MERRELL, 2006), irreversibilidade (CP 5.253, 5.421), continuidade (MS 875; PARKER, 1998, p. 75, p. 147), tendência ao infinito (EP 2: 478-483; CP 2,92, 2,303; ATKIN 2016, p. 136140), vagueza (CP 5.447), generalidade (CP 6.172 ; POTTER, 1997, p. 89), crescimento (EP 1: 313; 2:10; 2: 937).

A cantoria é um SCD. Ela é um SCD, porque atua como um processo semiótico. Imaginemos a cena - em uma cantoria, um cantador toca a viola e improvisa versos que "cabem" em um mote (ou deixa), após uma toada. O que observamos nessa cena? Em uma abordagem baseada em tarefas, observamos um agente, ou uma dupla de agentes, e diversos artefatos, os quais são objetos materiais que possuem certas propriedades, com fluxos de informaçóes para realização da tarefa. Uma abordagem semiótica produz uma descrição diferente da mesma cena - observamos o signo da cantoria em ação, em um processo semiótico que determina, descendentemente, o padrão de ação dos cantadores, violas, versos, motes, audiência etc. ${ }^{15}$ A cantoria é um signo em ação, uma regularidade que emerge de uma história passada em direção a um futuro possível. Ao invés de indivíduos e artefatos, observamos signos que

\footnotetext{
${ }^{15}$ A noção de determinação descendente (downward determination) refere-se à influência restritiva das condiçôes de contorno de nível superior sobre os objetos descritos em um nível de observação mesoou focal (QUEIROZ; EL-HANI, 2012). Na determinação descendente, as condições de contorno de nível superior coordenam ou regulam a dinâmica observada no nível focal.
} 
determinam comportamentos regulares de ação. Os cantadores, curadores, público, violas, toadas, motes e deixas são signos em ação.

Tomemos a viola como um exemplo. Trata-se de um artefato com diversas propriedades. Todavia, quando observamos a cantoria, não estamos observando as propriedades de uma viola, como um instrumento musical. Estamos observando a viola como um signo - a regularidade contextualizada de ação de um signo incorporada em uma viola, uma trajetória histórica de usos da viola e uma tendência à regularidade que essa história determina. $\mathrm{O}$ uso da viola não é explicado por suas disposiçóes técnicas e materiais mais os estados representacionais de um sistema que trabalha em direção a uma meta. A viola é um signo que representa e incorpora, para alguém, mais do que a si-mesma como um instrumento.

A viola, como um signo, tem um objeto que é ao mesmo tempo um sistema de regras (por exemplo, determinando a afinação), uma gramática, uma tradição de uso e manipulação, uma tradição de design e fabricação, o baiâo-de-viola, o qual é o ciclo regular de acordes que regulam a improvisação, e suas restriçóes rítmicas e métricas, o desafio da improvisação etc. Mais abrangentemente, a viola representa, para alguém, outro signo, que é mais geral - o processo do repente. Ela é o signo de um processo metassemiótico.

Afirmar que algo é um "signo em ação" equivale a afirmar que possui uma estrutura, uma hierarquia e uma lógica específicas. A estrutura é de uma relação triádica irredutível, que tem uma tendência para exibir um comportamento regular. $\mathrm{Na}$ descrição de Peirce, essa tendência se desenvolve através de fases inferenciais logicamente subsequentes: abduçáo, dedução e indução (HOOKWAY, 2002, p. 273; FORSTER, 2011, p. 144). A abdução é uma inferência ampliativa que começa com a observação de um resultado surpreendente, o qual não se adequa aos hábitos e expectativas do observador, e culmina com a formação e seleção de uma hipótese sobre como submeter esse resultado a padróes regulares (PAAVOLA, 2012). Como um "ato de insight", que "chega até nós como um flash" (CP 5.181), a abdução é responsável pela "descoberta” e usualmente é associada à criatividade. A dedução é uma inferência não ampliativa que elabora as consequências necessárias, ou estatísticas, da formulação de hipóteses (FORSTER, 2011, p. 141-144). A indução é uma inferência ampliativa que testa a hipótese formulada pela abdução e examinada pela dedução. A indução compara os resultados da dedução com os resultados dos testes experimentais (FORSTER, 2011, p. 147). 
Para Peirce, a inferência está relacionada à distribuição temporal da semiose (W 2:240). Fases inferenciais contínuas generalizam o passado e o atualizam no presente. A semiose forma uma trajetória, um desenvolvimento temporal que possui a propriedade de continuidade, não sendo apenas uma sequência de presentes (CP 6.111). A cantoria, como um signo que se desenvolve no tempo, incorpora uma estrutura inferencial. Para uma descrição semiótica da cantoria, como um SCD, deve-se enfatizar que o sistema acontece no tempo, através de relaçóes inferenciais. Como um signo em ação, a cantoria possui regularidade diante de situaçóes locais, de eventos específicos, de resultados incomuns e surpreendentes. Embora um SCD possa ser escalonado (zoom-in) em subtarefas, uma descrição do SCD, como um processo semiótico, deve ser capaz de decompô-lo em fases inferenciais. São processos inferenciais no sistema que são logicamente (não cronologicamente) subsequentes e cujo resultado é a cantoria como um padrão semiótico regular.

- A abdução é a fase lógica que explica como o sistema se adapta a novas situaçôes. Por exemplo, os cantadores devem responder a novos temas, contextos e situaçóes, e devem apresentar novos modos de incluir essas novidades em estruturas versificadas que podem representar a regularidade dos efeitos do signo (cantoria). Nesse caso, os artefatos cognitivos funcionam como ferramentas abdutivas (QUEIROZ; ATÃ, 2019), ajudando a gerar hipóteses de acordo com resultados previstos.

- A dedução é a fase que avalia as respostas abdutivas conforme as normas e regras envolvidas na cantoria, e verifica se as respostas são consistentes de acordo com as regras. Por exemplo, se um cantador compóe um verso, ele deve rimar com outros e, baseado na "deixa", o oponente deve manter a consistência de rimas. Nesse caso, os artefatos cognitivos funcionam, ajudando a restringir o comportamento em direção a um conjunto regular e robusto de consequências.

- A indução é a fase que explica como o sistema avalia as etapas abdutivas e dedutivas, para manter a estabilidade da cantoria como signo em ação. Por exemplo, o público reage positiva ou negativamente às inovaçóes propostas pelos cantadores. Nesse caso, os artefatos cognitivos ajudam na realização de experimentos, facilitando julgamentos perceptivos, quando, por exemplo, o baiấo- 
de-viola ajuda a comparar o tempo de resposta dos repentistas, ou quando a toada ajuda a identificar inconsistências métricas.

Conforme essa descrição, a atividade inferencial é incorporada no SCD como uma tendência geral. $\mathrm{O}$ resultado da atividade inferencial é que uma cantoria (ou uma sessão de repente) é capaz de atuar (enact) o repente, como um signo. ${ }^{16} \mathrm{O}$ sistema gera, desenvolve e avalia a semiose, para materializar e incorporar a cantoria. Trata-se de uma reformulação semiotizada da noção de SCD não centrada no agente. Os SCDs são identificados com base em processos semióticos. O que é mais decisivo aqui é que o SCD atua (enact) um signo. O que organiza os diferentes elementos do SCD é um nível metassemiótico que se sobrepóe a tipos distintos de processos semióticos.

A cantoria é um processo metassemiótico auto-organizado. Mas o que significa isso? Uma abordagem externalista explora como um signo se desenvolve em uma cadeia semiótica. Se o objeto do signo (em ação) é outro signo, o interpretante também é outro signo. Esta é uma relação triádica genuína, na qual todos os correlatos são signos (CP 2.92). Quando analisados, em várias escalas, observamos tríades e cadeias de tríades de diferentes tamanhos e níveis de complexidade. Um signo pode submeter a semiose a condiçôes muito específicas. Este é um processo metassemiótico que investiga a própria semiose. Noë (2015) descreveu a arte como uma "ferramenta estranha" (strange tool) para a investigação filosófica de práticas, técnicas e tecnologias que organizam nossas vidas.

\footnotetext{
${ }^{16}$ Muita discussão sobre a melhor tradução desse termo (enaction) para o português tem sido travada. O conceito de enaction faz referência ao acoplamento estrutural e codeterminação entre ação perceptiva e mundo percebido, em contraposiçáo à ideia de conteúdos mentais determinados por propriedades de um objeto externo. Algumas ediçóes, espanhola e portuguesa, traduzem enact por "enacción" e "enacçãa", respectivamente. A ediçâao brasileira (VARELA et al., 2003) prefere o termo "atuação". "Enativismo" significa "atuacionismo", e uma abordagem "enativa" é "atuacionista". Alternativas para "atuar" poderiam constituir neologismos como "enagir" (conforme sugerido por um parecerista anônimo) ou "enatuar". Decidimos, entretanto, seguir o uso estabelecido por parte da literatura especializada, em português brasileiro, mesmo conscientes de que "atuaçáo," em seu uso corrente e vernacular, não corresponde exatamente ao conceito de "enação". É importante, nesse caso, separar o uso técnico do termo "atuar" de seu sentido geral encontrado em dicionário. Quando afirmamos que a cantoria é "atuada", aludimos ao que, em inglês, poderia ser expresso como cantoria is enacted. Esse uso tira vantagem da proximidade do conceito de enaction com o verbo em inglês to enact, ou "pôr em execução". Quando afirmamos que um signo é atuado, pretendemos afirmar que ele é codeterminado por agentes e ambientes, que essa codeterminação é ativa e que implica necessariamente uma prática situada, sem a qual o signo-em-si não existe como tal.
} 
Em nossa descrição, a cantoria equivale a uma investigação metassemiótica. O diálogo improvisado da cantoria é uma estranha conversa, com começo e fim convencionalizados, regras rígidas de interlocução, padrôes de repetição regulares, um vencedor e um perdedor. Trata-se de um diálogo improvisado que submete a língua natural a condiçóes rigorosas e incomuns de restrição, atuando em vários níveis descritivos - temporal, métrico, rímico, rítmico, dialógico, situacional.

\section{Consideraçóes finais: Semiótica cognitiva Peirciana e os SCDS}

Neste artigo, introduzimos o externalismo cognitivo ativo de Peirce. Em seguida, exploramos como a abordagem semiotizada de um SCD tem implicaçóes para a descrição de um modelo exemplar de cognição distribuída: a cantoria de viola ou repente. A cantoria funciona, de acordo com nossa abordagem, como um modelo de cognição distribuída em que uma tarefa - geração instantânea, improvisada, de versos, em um diálogo competitivo - é dependente da interação de diversos indivíduos (repentistas, apologistas, curadoria, audiência) e artefatos (violas, toadas, estruturas métricas, rimas, estruturas rítmicas e prosódicas). Semiotizamos a cantoria, sugerindo uma ontologia semiótica para o fenômeno - não se trata apenas uma comunidade de cérebros (processadores de informação) em interação; trata-se de um signoem-ação (ou semiose), atuando sobre artefatos e indivíduos. Para fornecer uma ontologia capaz de explicar seu caráter distribuído, não individual, é necessário que o externalismo ativo seja associado a uma teoria do significado. A cogniçãao é distribuída, porque consiste na ação de signos, um processo externo e distribuído.

Em nossa descrição, a propriedade de distribuição temporal, nos SCDs e seus componentes como signos em ação, ocupa um papel crucial. Uma questão básica em nossa abordagem é: o que torna uma entidade qualquer um componente de um SCD? O que a torna parte de um SCD é sua atuação como um termo relacional que está para um segundo termo de modo a determinar um terceiro, que é um efeito regular. Processos semióticos são processos autocorretivos, cuja estrutura lógica exibe uma relação irredutível entre três termos (signo-objeto-interpretante). Uma entidade torna-se parte de um SCD, porque atua como um signo. Há aqui um problema metodológico: por que descrever os SCDs como semiose? 
A resposta é que não podemos explicar (porque não é suficiente) o comportamento de um SCD como "efeito" produzido por indivíduos, grupos de indivíduos e artefatos. O fenômeno mais importante, em nossa abordagem, é a ação dos signos. Indivíduos e artefatos, em um SCD, são observados como processos de/em relaçóes triádicas irredutíveis. A unidade fundamental de explicação para o comportamento de indivíduos e artefatos, em um SCD (e esta é provavelmente a mais importante contribuição dessa abordagem) é a semiose, coordenando indivíduos e artefatos em comportamentos regulares.

Enfatizamos que a semiose é um processo e existe na forma de ação, ocorrência e mudança. Essa propriedade, salientada por apenas alguns pesquisadores (ver FISCH, 1986), ainda é timidamente explorada em casos particulares de análise. A estabilidade da semiose, como um processo estendido no tempo, não é entendida como stasis (estados representacionais estáticos), mas como regularidade da ação. Em nosso argumento, a distribuição da cognição é uma consequência necessária da natureza da semiose - ela é distribuída no tempo e no espaço como um processo materialmente incorporado. É bem conhecido como Hutchins (2014) caracterizou a cognição distribuída como uma abordagem emergentista. Em nossa abordagem, a semiose é um processo temporalmente distribuído, no qual uma tendência regular para gerar certos resultados emerge de um histórico de interaçóes de signos.

O que chamamos aqui de "externalismo semiótico" identifica a cantoria como um sistema (SCD) que incorpora a ação do signo. Em nossa descrição, a cantoria é um signo em ação. Seu objeto é a linguagem natural, na forma de um diálogo ou conversa. Seu interpretante é uma tendência para gerar metassemiose. A ação do signo pode ser assim estruturada: o sistema submete a linguagem a situaçôes incomuns, na forma de um diálogo, que é um desafio de improvisação. Então, indivíduos e artefatos oferecem soluções para o desafio, em um processo lógico de geração de conjecturas (fase abdutiva), desenvolvidas consistentemente, de acordo com as regras da tarefa e de solução de problemas (fase dedutiva). Em seguida, o sistema avalia os resultados (fase indutiva) para formar tendências e regularidades de ação. Na cantoria, a semiose inclui situaçôes surpreendentes, nutrindo-se através de novos interpretantes. Esse poder para geração de interpretantes, os quais se tornam signos que produzem outros interpretantes (ou, em outras palavras, a capacidade dos signos para gerar mais signos), é a propriedade mais fundamental da cognição, na semiótica de Peirce, e é aquela que fornece a base para uma abordagem externalista e semiótica da cognição distribuída. 
Agradecimentos: Agradecemos aos pareceristas pelas valiosas críticas e sugestôes e, especialmente, aos cantadores com quem estivemos, entre muitas conversas, filmagens e entrevistas, em novembro e dezembro de 2019, nos estados da Paraíba, Pernambuco e Ceará: Nilson Martins, Toinho Batista, Edmilson Silva, José Viana, Sebastiāo Dias, Tião, Fredi Guimarães, Ivanildo Vila Nova, Iponax Vila Nova, Edmilson Ferreira, Tindara, Siba, Antonio Lisboa, Guerreira.

ATÃ, P.; QUEIROZ, J. The active semiotic externalism of C. S. Peirce and the "Cantoria de viola" as a sign in action. Trans/form/ação, Marília, v. 44, n. 3, p. 177-204, Jul./Set., 2021.

\begin{abstract}
The main purpose of this work is to provide a semiotic ontology for redescription of active cognitive externalism, recently developed by the paradigm 4E (embodied, embedded, enactive, extended cognition). In our approach, distributed cognitive systems (DCSs) are described as semiosis, signs in action. We explored the relationship between semiosis and cognition, as conceived by C. S . Peirce, in association with the notion of distributed cognitive system (DCS). We introduce Peircean externalist approach with an emphasis on the notion of temporal distribution of semiosis, and describe DCSs, and their elements, as "sign in action". To develop this argument, we describe an example of DCS -- verbal-musical improvisation of repente, repentismo, or viola singing. It is a phenomenon of verbal-musical improvisation that takes the form of a challenge in versified oral poetry. We describe the phenomenon as the embodiment of the formal structure of a cognitive task and an inferential process. This embodiment corresponds to a semiotization of the repente performances as DCSs. The temporally distributed tendency of repentismo organizes the DCS as a system that performs metasemiotic experiments on the action of signs.
\end{abstract}

Keywords: Distributed cognitive system. Active externalism. Semiosis. Repentismo. C. S. Peirce.

\title{
REFERÊNCIAS
}

ATÃ, P; QUEIROZ, J. Icon and abduction: situatedness in Peircean cognitive semiotics. In: MAGNANI, L. (org.). Model-based reasoning in science and technology. New York: Springer, 2013. p. 301-313.

ATÃ, P.; QUEIROZ, J. Iconicity in Peircean situated cognitive semiotics. In: THELLEFSEN, T.; SORENSEN, B. (org.). Charles Sanders Peirce in his own words: 100 years of semiotics, communication and cognition. Berlin: Walter de Gruyter, 2014. p. 527-536. 
ATÃ, P.; QUEIROZ, J. Emergent sign-action: classical ballet as a self-organized and temporally distributed semiotic process. European journal of pragmatism and american philosophy-EJPAP, v. XI, n. 2, 2019a. Disponível em: shttps://doi.org/10.4000/ ejpap.1652. Acesso em: 14 abr. 2021.

ATÃ, P; QUEIROZ, J. Semiosis is cognitive niche construction. Semiotica, v. 228, p. 3-16, $2019 \mathrm{~b}$.

ATKIN, R. Peirce. Abingdon: Routledge, 2016.

BENDER, A.; BELLER; S. The Power of 2: How an apparently irregular numeration system facilitates mental arithmetic. Cognitive science, v. 41, p. 158-187, 2017.

BERNSTEIN, R. J. Pragmatic turn. Cambridge: Polity, 2010.

BICKHARD, M. Some consequences (and enablings) of process metaphysics.

Axiomathes, v. 21, n. 1, p. 3-32, 2011.

BJORNDAHL, J. S.; FUSAROLI, R.; ØSTERGAARD, S.; TYLÉN, K. Thinking together with material representations: joint epistemic actions in creative problem solving. Cognitive semiotics, v. 7, n. 1, p. 103-123, 2014.

BRUNNING, J. Genuine triads and teridentity. In: HOUSER, N.; ROBERTS, D.; EVRA, J. (org.). Studies in the logic of Charles Sanders Peirce. Indiana: Indiana University Press, 1997. p. 252-270.

BURCH, R. Peirce's reduction thesis. In: HOUSER, N.; ROBERTS, D.; EVRA, J. (org.). Studies in the logic of Charles S. Peirce. Indiana: Indiana University Press, 1997. p. 234-251.

CASCUDO, L. da C. Vaqueiros e cantadores. São Paulo: Global, 2004.

CHAMPAGNE, M. A less simplistic metaphysics: Peirce's layered theory of meaning as a layered theory of being. Sign systems studies, v. 43, n. 4, p. 523-559, 2015.

CLARK, A; CHALMERS, D. The extended mind. Analysis, n. 58, p. 7-19, 1998.

CLARK, A. Word, niche and super-niche: how language makes minds matter more. Theoria, n. 54, p. 255-268, 2005.

CLARK, A. Language, embodiment, and the cognitive niche. Trends in cognitive sciences, v. 10, n. 8, p. 370-372, 2006.

CLARK, A. Supersizing the mind: embodiment, action, and cognitive extension. Oxford: Oxford University Press, 2010.

COLAPIETRO, V. M. Peirce's approach to the self: a semiotic perspective on human subjectivity. New York: State University of New York Press, 1988.

DAVIES, J.; MICHAELIAN, K. Identifying and individuating cognitive systems: a task-based distributed cognition alternative to agent-based extended cognition. Cognitive processing, n.17, p. 307-319, 2016. 
DE WAAL, C. Peirce: a guide for the perplexed. London: Bloomsbury Academic, 2013.

EL-HANI, C.; QUEIROZ, J. Modos de irredutibilidade das propriedades emergentes. Scientiae Studia, v. 3, n. 1, p. 9-41, 2005.

ESPOSITO, J. Synechism: the keystone of Peirce's metaphysics. In: BERGMAN, M.; QUEIROZ, J. (org.). The commens encyclopedia: the digital encyclopedia of Peirce studies, 2005. Disponível em: http:/www.commens.org/encyclopedia/article/espositojoseph-synechism-keystone-peirce\%e2\%80\%99s-metaphysics. Acesso em: 14 abr. 2021.

FISCH, M. Just how general is Peirce's general theory of signs? In: KETNER, K. L.; KLOESEL, C. J. W. (org.). Peirce, semeiotic, and pragmatism. Indiana: Indiana University Press, 1986. p. 356-361.

FORSTER, P. Peirce and the threat of nominalism. Cambridge: Cambridge University Press, 2011.

GOMES, A.; EL-HANI, C.; GUDWIN, R.; QUEIROZ, J. Towards the emergence of meaning processes in computers from Peircean semiotics. Mind \& society: cognitive studies in economics and social sciences, n. 6, p. 173-187, 2007.

HOOKER, C. Philosophy of complex systems. Amsterdam: Elsevier, 2011.

HOOKWAY, C. Peirce. London: Routledge \& Kegan Paul, 1985.

HOOKWAY, C. Truth, rationality, and pragmatism: themes from Peirce. Oxford: Clarendon Press, 2002.

HUTCHINS, E. Cognition in the wild. Cambridge, Massachusetts: MIT Press, 1995a.

HUTCHINS, E. How a cockpit remembers its speeds. Cognitive science, n. 19, p. 265288, 1995b.

HUTCHINS, Ed. Cognitive artifacts. In: WILSON, R.; KEIL, F. (org.). The MIT encyclopedia of the cognitive sciences. Cambridge: MIT Press, 1999. p. 126-128.

HUTCHINS, E. Enculturating the supersized mind. Philosophical studies, v. 152, p. 437-446, 2011.

HUTCHINS, E. The cultural ecosystem of human cognition. Philosophical psychology, n. 27, p. 34-49, 2014.

KELSO, S. Dynamic patterns: the self-organization of brain and behavior. Cambridge, MA: MIT Press, 1995.

KIRSH, D. Problem solving and situated cognition. In: ROBBINS, P.; AYDEDE, M. (org.). The Cambridge handbook of situated cognition. Cambridge: Cambridge University Press, 2009. p. 264-306. 
LAU, J.; DEUTSCH, M. Externalism about mental content. In: ZALTA, E. N. (org.). The Stanford encyclopedia of philosophy (Fall 2019 Edition). Disponível em: https:// plato.stanford.edu/archives/fall2019/entries/content-externalism/. Acesso em: 14 abr. 2021.

LOULA, A.; GUDWIN, R.; EL-HANI, C.; QUEIROZ, J. The emergence of selforganized symbol based communication in artificial creatures. Cognitive systems research, n. 11, p. 131-147, 2010.

MENARY, R. (org.). The extended mind. Massachusetts: MIT Press, 2010.

MURPHEY, M. G. The development of Peirce's philosophy. Indianapolis, IN: Hackett, 1993.

NERSESSIAN, N. J. Creating scientific concepts. Cambridge: A Bradford Book. The MIT Press, 2008.

NERSESSIAN, N. J.; KURZ-MILCKE, E.; NEWSTETTER, W. C.; DAVIES, J. Research laboratories as evolving distributed cognitive systems. In: ALTERMAN, R.; KIRSH, D. (ed.). Proceedings of the twenty-fifth conference of the cognitive science society. Boston: Cognitive Science Society, 2003. p. 857-862.

NEWELL, A.; SIMON, H. Human problem solving. Englewood Cliffs: Prentice-Hall, 1972.

NEWEN, A.; DE BRUIN, L.; GALLAGHER, S. (ed.). The Oxford handbook of 4E cognition. Oxford: Oxford University Press, 2018.

NICHOLSON, D.; DUPRÉ, J. Everything flows: towards a processual philosophy of biology. Oxford: Oxford University Press, 2018.

NOË, A. Strange tools: art and human nature. New York: Hill and Wang, 2015.

OLIVEIRA, L. P. de. A música na cantoria em Campina Grande (PB): estilo musical dos principais gêneros poéticos. 1999. Tesse (Doutorado) - Universidade Federal da Bahia, Salvador, 1999.

PAAVOLA, S. On the origin of ideas: an abductivist approach to discovery. New York: Lap Lambert Academic, 2012.

PANDE, P.; CHANDRASEKHARAN, S. Representational competence: towards a distributed and embodied cognition account. Studies in science education, v. 53, n. 7267, p. 1-43, jun. 2017.

PARKER, K. The continuity of Peirce's thought. Nashville: Vanderbilt University Press, 1998.

PEIRCE, C. S. The collected papers of Charles Sanders Peirce. [C. Hartshorne, CP Weiss Eds. Cambridge-MA: Harvard University Press, 1931-1935], v. VII-VIII [AW Burks Ed. same publisher, 1958]; v. I-VI. Charlottesville: Intelex Corporation (citado como CP, seguido de volume e parágrafo), 1931-1935. 
PEIRCE, Charles S. Annotated catalogue of the papers of Charles S. Peirce. In: ROBIN, R. (org.). Manuscritos e cartas de Charles S. Peirce Amherst-MS: University of Massachusetts, 1967. [MS and L - de acordo com esse catálogo].

PEIRCE, C. S. Writings of Charles S. Peirce, v. 6. Ed. FISCH, M.; MOORE, E.; KLOESEL, C. (ed). Indianapolis: Indiana University Press, 1982 [citado como W seguido de volume número de página].

PEIRCE, C. S. The essential Peirce: selected philosophical writings. v. II, Peirce Edition Project (org.). Indianapolis: Indiana University Press, 1998. [1893-1913] - [citado como EP, seguido pelo número da página].

POTTER, V. Charles S. Peirce: on norms and ideals. New York: Fordham University Press, 1997.

QUEIROZ, J.; ATÃ, P. Intersemiotic translation as an abductive thinking tool. In: MARAIS, K. (org.). Complexity thinking in translation studies: methodological considerations. New York: Routledge, 2019. p. 19-32.

QUEIROZ, J.; EL-HANI, C. Semiosis as an emergent process. Transaction of Charles S. Peirce society, v. 42, n. 1, p. 78-116, 2006.

QUEIROZ, J.; EL-HANI, C. Downward Determination in Semiotic Multi-level Systems. Cybernetics \& human knowing: a journal of second order cybernetics, autopoiesis \& semiotics, n. 19, p. 123-136, 2012.

QUEIROZ, J.; EMMECHE, C.; KULL, K.; EL-HANI, C. The biosemiotic approach in biology: theoretical bases and applied models. In: TERZIS, G.; ARP, R. (ed.).

Information and living systems: philosophical and scientific perspectives. Cambridge, Massachusetts: MIT Press, 2011. p. 91-130.

QUEIROZ, J.; MERRELL, F. Semiosis and pragmatism: toward a dynamic concept of meaning. Sign system studies, v. 34, n. 1, p. 37-66, 2006.

QUEIROZ, J.; STJERNFELT, F. (org.). Peirce's extended theory and classification of Signs. Semiotica, v. 228, 2019.

RAMALHO, E. B. Cultura oral em novos estudos: a cantoria nordestina. O Público e o privado, n. 1, p. 7-30, 2001.

RANSDELL, J. Some leadings ideas of Peirce's semiotic. Semiotica, n. 19, p. 157-178, 1977.

RANSDELL, J. The relevance of Peircean semiotic to computational intelligence augmentation. SEED Journal, v. 3, n. 3, p. 5-36, 2003.

RESCHER, N. Process metaphysics: an introduction to process philosophy. New York: Suny, 1996.

ROSENTHAL, S. Charles Peirce's pragmatic pluralism. New York: State University of New York Press, 1994. 
SAUTCHUK, J. M. M. A poética do improviso: prática e habilidade no repente nordestino. 2009. Tesse (Doutorado) - Universidade de Brasília, Brasília, 2009.

SAUTCHUK, J. M. M. Poetic improvisation in the Brazilian Northeast. Vibrant: virtual Brazilian anthropology, n. 8, p. 260-290, 2011.

SAVAN, D. Response to Thomas L. Short. Transactions of the Charles S. Peirce Society, v. 22, n. 2, p. 125-143, Summer 1986.

SEIBT, J. Process philosophy. In: ZALTA, E. N. (org.). The Stanford encyclopedia of philosophy, 2018. Disponível em: https://plato.stanford.edu/archives/spr2018/entries/ process-philosophy/ Acesso em: 14 abr. 2021.

SINHA, C. Language as a biocultural niche and social institution. In: EVANS, V.; POURCEL, S. (org.). New directions in cognitive linguistics. Amsterdam: John Benjamins, 2009. p. 239-310.

SINHA, C. Language and other artifacts: socio-cultural dynamics of niche construction. Frontiers in psychology, n. 6, 2015. Disponível em: https://doi.org/10.3389/ fpsyg.2015.01601 Acesso em: 14 abr. 2021.

SKAGESTAD, P. Peirce's inkstand as an external embodiment of mind. Transactions of the Charles S. Peirce society, v. 35, n. 3, p. 551-561, 1999.

SPURRETT, D. Why think that cognition is distributed? Alternation, v. 10, n. 1, p. 292-306, 2003.

STERELNY, K. Externalism, epistemic artefacts and the extended mind. In: SHANTZ, R. (ed.). The Externalist Challenge. Berlin, New York: Walter de Gruyter, 2004. p. 239-254.

SUTTON, J. Exograms and interdisciplinarity: history, the extended mind, and the civilizing process. In: MENARY, R. (ed.), The extended mind. Cambridge, MA: MIT Press, 2010. p. 189-225.

VARELA, F.; THOMPSON, E.; ROSH, E. A mente incorporada: ciências cognitivas e experiência humana. Porto Alegre: Artmed, 2003.

WEBER, M.; WEEKES, A. (org.) Process approaches to consciousness in psychology, neuroscience, and philosophy of mind. New York: Suny, 2009.

WILSON, L. Roteiro de velhos cantadores e poetas populares do sertáo. Recife: CEHM, 1986.

ZHANG, J.; NORMAN, D. Representations in distributed cognitive tasks. Cognitive science, n. 18, p. 87-122, 1994.

ZHANG, J.; WANG, H. The effect of external representations on numeric tasks. The quarterly journal of experimental psychology, section A, v. 58A, n. 5, p. 817-838, 2005

Recebido: $18 / 9 / 2020$

Aceito: $03 / 3 / 2021$ 
ATÁ, P.; QUEIROZ, J. 